\title{
Comparison of Transmissibility of Non-Metallic Materials For Vibration Isolation
}

\author{
A. R. Lavhande, S. B. Tuljapure \\ (Department of Mechanical Engineering, Walchand Institute of Technology, Solapur, India)
}

\begin{abstract}
Vibrations in the machines are introduced during operation due unbalanced forces. Therefore it should be eliminated or at least reduced. Vibration can be reduced by introducing the isolation between the vibration source and receiver. In this paper, the vibrations generated due to gyroscope coupled with variable speed motor are analyzed and reduced using nonmetallic isolators. The materials used are cork, rubber, and neoprene. The transmissibility is compared for three different speeds. For measuring the vibrations, FFT analyzer is used.
\end{abstract}

Keywords : FFT Analyzer, Isolator, Transmissibility, Vibration isolation.

\section{Introduction}

Vibrations occur in most of machines. A vibration problem is nicely described by the source - path receiver model. Source is a mechanical or fluid disturbance, generated internally by the machine, such as unbalance, torque pulsations, gear tooth meshing, fan blade passing, etc. Path is the structural or airborne path by which the disturbance is transmitted to the receiver. Receiver is the responding system, generally foundation or base structure. The objective of this paper is to analyze the vibrations induced in gyroscope coupled with varying speed motor and to analyze and compare the vibrations after using isolator. Compare the transmissibility to check which material for better isolation.

\section{Vibration Isolation}

Vibration isolation is defined as the prevention of vibrations from entering a system or we can also define transmissibility as the percent of vibrational energy that is being transmitted through a structure.

Mathematically these two terms are simply related.Transmissibility is a measure of the reduction of transmitted force or motion afforded by an isolator. Transmissibility is the ratio of the force amplitude transmitted to the foundation to the amplitude of the exciting force. Thus transmissibility can be formulated as:

$$
T=\left|\frac{F_{T}}{F_{O}}\right|=\left|\frac{X}{Y}\right|
$$

Where $\mathrm{T}$ is the Transmissibility ratio FT is force transmitted, Fo is exciting force, $\mathrm{X}$ is motion transmitted, $\mathrm{Y}$ is motion excited by the source. The effectiveness of the isolator, expressed in per cent is:

$\%$ Isolation $=(1-T) * 100$

If the vibration frequency is not constant or if the vibration involves a large number of frequencies, the desired reduction of vibration may not be attainable by altering the natural frequency of the responding system. It may be possible to achieve equivalent results by the dissipation of energy to eliminate the severe effects of resonance. Generally the isolators are springs, pads and mounts. Generally, Materials used for isolator are steel for spring; neoprene, rubber etc. are preferred for pad and mounts. In this paper the transmissibility for cork, rubber and neoprene are compared.

\subsection{FFT Analyzer}

FFT analyzers are used for the measurement of vibration. It consists of accelerometer used as sensor. Accelerometer is connected to the vibrating base with the help of adhesive and it senses the vibratory motion. FFT analyzers make use of the FFT (fast Fourier transform) algorithm to calculate the spectra of blocks of data. FFT analyzers produce a (complex) spectrum with a number of spectral lines equal to half the number of (real) time samples transformed. 


\subsection{Problem Identification}

\section{Experimentation}

The experimental setup of gyroscope coupled with variable speed motor has vibrations. The amplitude of vibration increases with increase in speed. The vibrations in gyroscope are transferred to wooden table. This vibration causes table to vibrate. The gyroscope is coupled with the variable speed motor whose speed can be adjusted with the help of regulator. As the speed of the motor is varied from $1 \mathrm{rpm}$ to above, the vibrations are also increased which can be sensed at the foundation table.

\subsection{Experimental Procedure}

In the work, experimental setup of gyroscope coupled with variable speed motor is used. The whole setup is rested on wooden table. The unbalanced forces are produced in rotating motor causes base to vibrate. Different nonmetallic material pads are used as isolator to attenuate vibrations and regulator is used to vary the speed of motor. Here the gyroscope is vibration source and wooden table is vibration receiver. The isolator pads of rubber are kept in between them as path. The motor speed can be varied from 0 to $3000 \mathrm{rpm}$ by adjusting the voltage regulator. The base of gyroscope has $30 \mathrm{~cm}$ diameter and is rested on wooden table. Four isolator pads are used for isolation purpose. The materials used for the isolator are cork, rubber and neoprene. These pads are kept between base and wooden table. The dimensions of material for isolator are taken as same. Each isolator has $5 \mathrm{~mm}$ thickness and $50 \mathrm{~mm}$ length and width. The vibrations are analyzed for three different speeds viz. $1000 \mathrm{rpm}, 1600 \mathrm{rpm}$, and $2200 \mathrm{rpm}$ and spectrum is taken using FFT analyzer.Oros NV gate 8.0 FFT analyzer is used to measure the acceleration at different speeds. The accelerometer sensor is attached to table with the help of adhesive. The experiment is carried out in two stages. In the first stage, the speed is adjusted and graph is recorded. This gives values of vibration induced in the setup. In second stage, the four isolator pads are kept between setup and the base (red dots shown in figure) and graph is recorded. This gives the values of vibration transmitted through rubber pad isolator to base. The gyroscope coupled to the motor is shown in Fig. 1

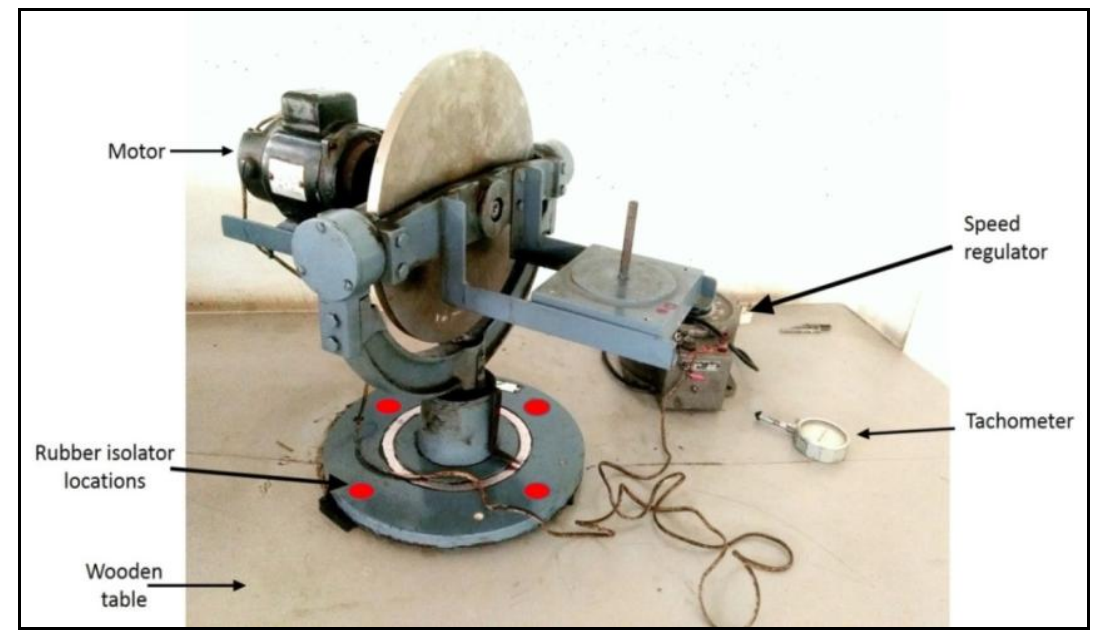

Fig. 1 Gyroscope coupled with varying speed motor experimental setup

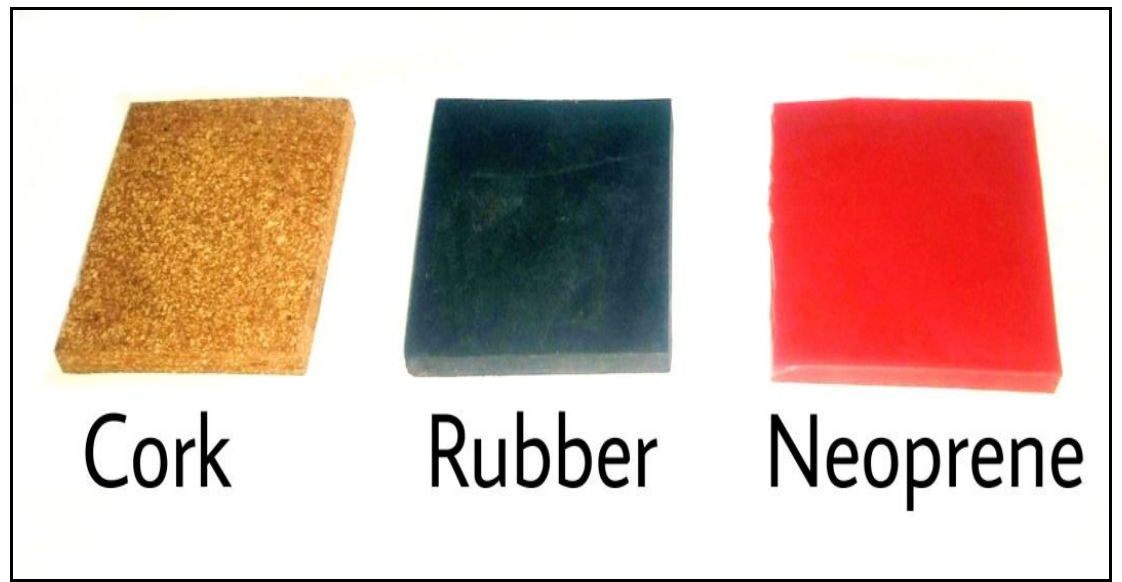

Fig. 2 Isolators used for the experimental work 


\section{Results and Discussions}

The data obtained is tabulated as follows. The transmissibility is calculated using equation 3 given above.

Table 1: Transmissibility analysis of CORK pad for different speeds

\begin{tabular}{|c|c|c|c|c|}
\hline \multirow{2}{*}{$\begin{array}{l}\text { Speed } \\
(\mathbf{r p m})\end{array}$} & \multicolumn{2}{|c|}{ RMS value of Acceleration } & \multirow{2}{*}{$\begin{array}{c}\text { Transmissibility } \\
\text { Ratio } \\
\text { T.R.= Xt/Xo }\end{array}$} & \multirow{2}{*}{$\begin{array}{c}\text { Effectiveness of } \\
\text { Isolation } \\
(1-\text { T.R. }) * 100 \\
(\%)\end{array}$} \\
\hline & $\begin{array}{l}\text { Without isolator } \\
(\mathrm{Xo}), \mathrm{m} / \mathbf{s}^{2}\end{array}$ & $\begin{array}{l}\text { With isolator } \\
(\mathrm{Xt}), \mathrm{m} / \mathrm{s}^{2}\end{array}$ & & \\
\hline 1000 & $850 \mathrm{E}-06$ & $398 \mathrm{E}-06$ & 0.4682 & 53.17 \\
\hline 1600 & $1.075 \mathrm{E}-03$ & $655 \mathrm{E}-06$ & 0.6093 & 39.07 \\
\hline 2200 & $1.804 \mathrm{E}-03$ & $997 \mathrm{E}-06$ & 0.5526 & 44.73 \\
\hline
\end{tabular}

Table 2: Transmissibility analysis of RUBBER pad for different speeds

\begin{tabular}{|c|c|c|c|c|}
\hline \multirow[b]{2}{*}{$\begin{array}{l}\text { Speed } \\
(\text { rpm })\end{array}$} & \multicolumn{2}{|c|}{ RMS value of Acceleration } & \multirow{2}{*}{$\begin{array}{c}\text { Transmissibility } \\
\text { Ratio } \\
\text { T.R.= Xt/Xo }\end{array}$} & \multirow{2}{*}{$\begin{array}{c}\text { Effectiveness of } \\
\text { Isolation } \\
(1-\text { T.R. }) * 100 \\
(\%)\end{array}$} \\
\hline & $\begin{array}{l}\text { Without isolator } \\
(\mathrm{Xo}), \mathbf{m} / \mathbf{s}^{2}\end{array}$ & $\begin{array}{l}\text { With isolator } \\
(\mathrm{Xt}), \mathbf{m} / \mathbf{s}^{2}\end{array}$ & & \\
\hline 1000 & $850 \mathrm{E}-06$ & $704 \mathrm{E}-06$ & 0.8282 & 17.18 \\
\hline 1600 & $1.075 \mathrm{E}-03$ & $981 \mathrm{E}-06$ & 0.9125 & 8.70 \\
\hline 2200 & $1.804 \mathrm{E}-03$ & $1.513 \mathrm{E}-03$ & 0.8387 & 16.13 \\
\hline
\end{tabular}

Table 3: Transmissibility analysis of NEOPRENE pad for different speeds

\begin{tabular}{|c|c|c|c|c|}
\hline \multirow{2}{*}{$\begin{array}{l}\text { Speed } \\
(\mathbf{r p m})\end{array}$} & \multicolumn{2}{|c|}{ RMS value of Acceleration } & \multirow{2}{*}{$\begin{array}{c}\text { Transmissibility } \\
\text { Ratio } \\
\text { T.R.= Xt/Xo }\end{array}$} & \multirow{2}{*}{$\begin{array}{l}\text { Effectiveness of } \\
\text { Isolation } \\
(1-\text { T.R. }) * 100 \\
(\%)\end{array}$} \\
\hline & $\begin{array}{l}\text { Without isolator } \\
(\mathrm{Xo}), \mathrm{m} / \mathrm{s}^{2}\end{array}$ & $\begin{array}{l}\text { With isolator } \\
(\mathrm{Xt}), \mathrm{m} / \mathrm{s}^{2}\end{array}$ & & \\
\hline 1000 & $850 \mathrm{E}-06$ & $680 \mathrm{E}-06$ & 0.8 & 20 \\
\hline 1600 & $1.075 \mathrm{E}-03$ & $695 \mathrm{E}-06$ & 0.6465 & 35.35 \\
\hline 2200 & $1.804 \mathrm{E}-03$ & $785 \mathrm{E}-06$ & 0.435 & 56.5 \\
\hline
\end{tabular}

For data obtained it is seen clearly that with increase in the speed, the vibration also increases. For low speeds the vibrations are less. For high speed the neoprene shows great reduction in vibration. The effectiveness of isolation of neoprene at high speeds is $56.5 \%$, while of cork is $44.73 \%$. The effectiveness of isolation for cork material as isolator remains constant for low to high speeds. The transmissibility is calculated for each material at different speeds. The cork provides minimum average value of transmissibility $=0.543$, neoprene provides average value of transmissibility $=0.627$, while rubber provides average value of transmissibility $=$ 0.86 . The vibration spectrum recorded using FFT analyzer for high speed i.e. $2200 \mathrm{rpm}$ is shown in figure below. The graph gives clear idea of reduction of vibration. The spectrum is frequency in hz. vs. acceleration in $\mathrm{m} / \mathrm{s}^{2}$. The spectrum shows peak values of vibration before and after isolation.

\section{Conclusions And Future Scope}

The vibration increases with increase in speed of motor. The main purpose of this work is to compare the transmissibility of nonmetallic materials. Cork shows reliable and good isolation behavior. From the discussions it is come to know that the cork shows good isolation property. Depending upon the results obtained and mean effectiveness of isolation, the materials for isolator pads can be arranged as Rubber < Neoprene < Cork.In fig 6, it can be seen that when compared to rubber and cork, neoprene greatly reduces the vibrations. The effectiveness of isolation of neoprene pad for $2200 \mathrm{rpm}$ is $44.73 \%$. Cork pad is suitable for low as well as high speeds.Rubber is used as isolator in machine workshop, but neoprene also shows good isolation property. As compared to cork and neoprene the rubber is less costly and thus more thick rubber pads can be used for isolation purpose. For precise vibration isolation cork should be used as isolator. The combination of rubber and cork can reduce the vibrations. 


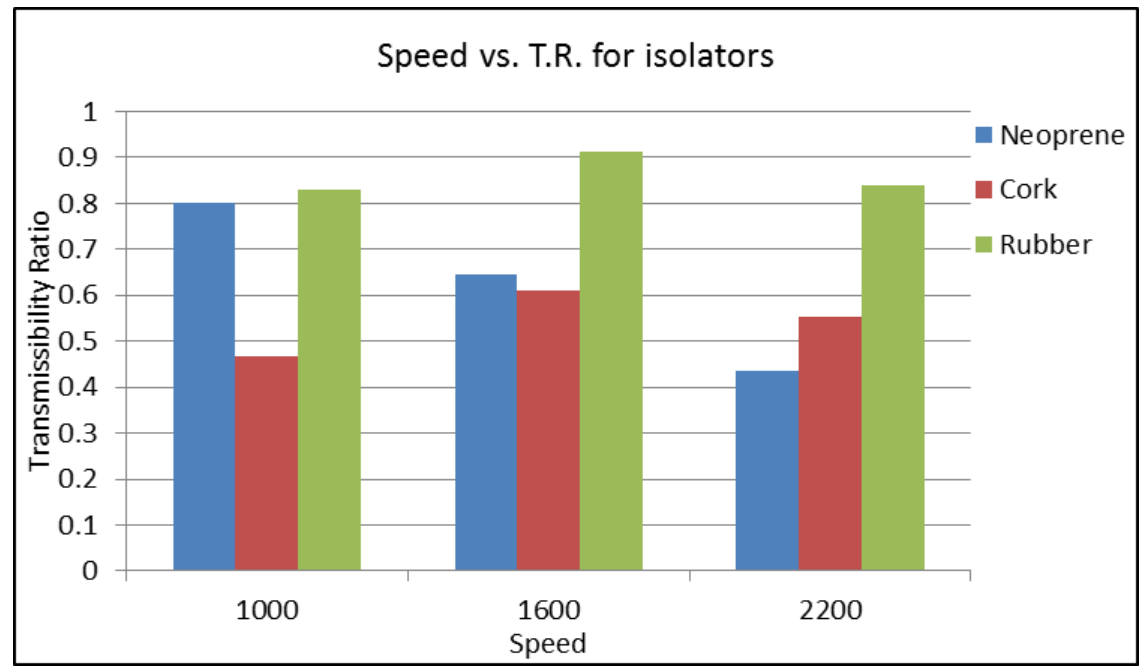

Fig. 3 Speed vs. Transmissibility ratio for isolators

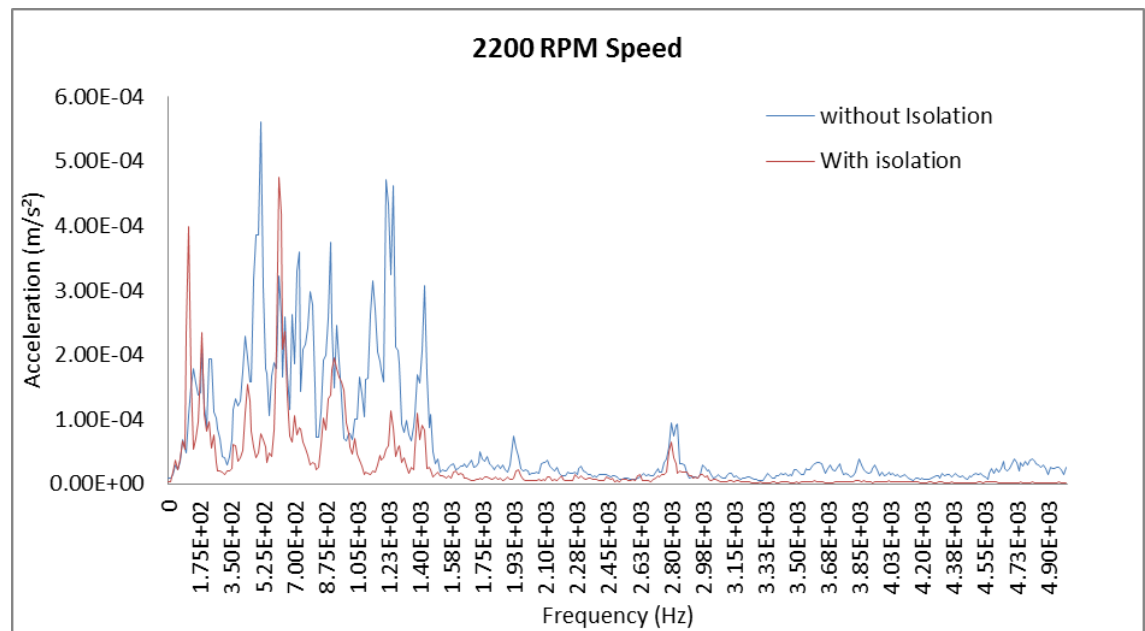

Fig. 4 vibration spectrum for Cork material as isolator

\section{Acknowledgements}

I would like to express my sincere gratitude to our Principal Dr. S. A. Halkude and Dr. P. R. Kulkarni (Head of Mechanical Engineering Department) for giving me the opportunity to widen the knowledge and also for their constant encouragement and inspiration during project work. Also I am very thankful to my guide Prof. S. B. Tuljapure for giving much of their valuable time, precious guidance.

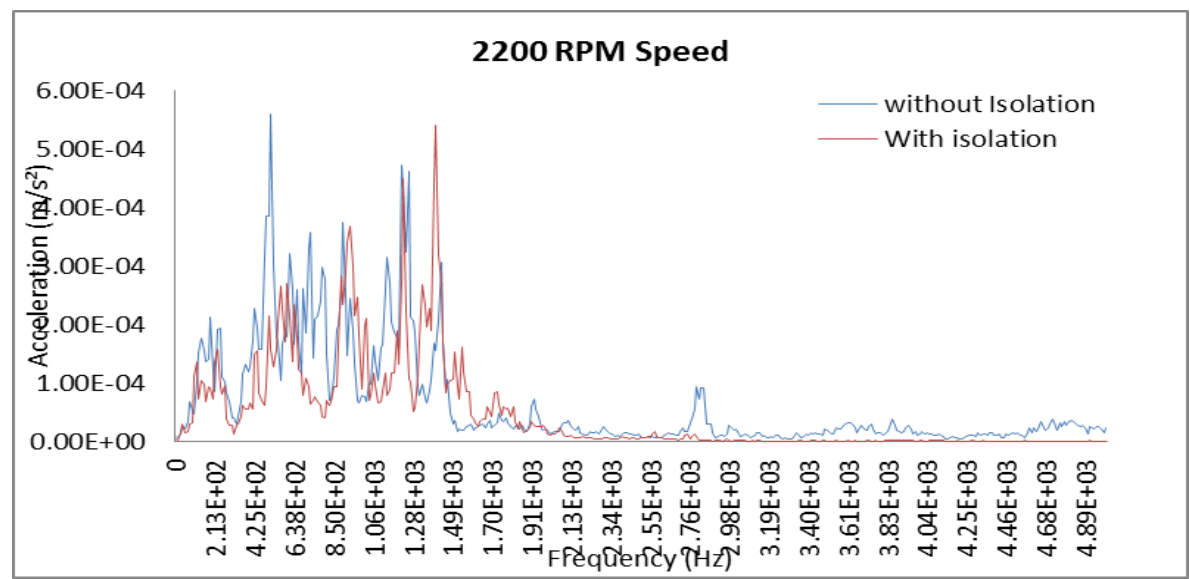

Fig. 5 vibration spectrum for Rubber material as isolator 


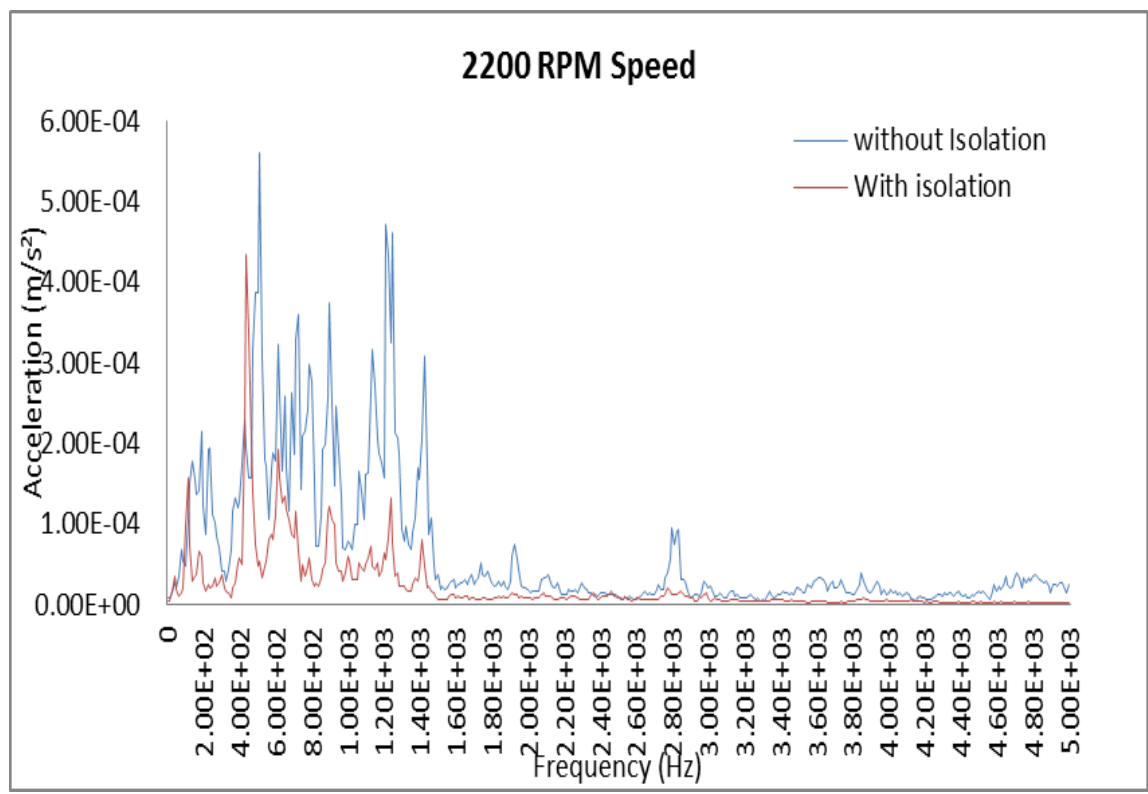

Fig. 6 Vibration spectrum for Neoprene material as isolator

\section{References}

[1]. A. Tiwari, A. Chandsarkar, Analyze the transmissibility of various materials using vibration analysis, International journal of engineering sciences \& research Technology,3(8),2014,247-251.

[2]. D. D. L. Chung, Review materials for vibration damping, Journal of material science 36,2001,5733-5737.

[3]. Chen Xueqian, Shen Zhanpeng, He Qinshu, Du Qiang \& Liu Xinen ,Influence of uncertainty and excitation amplitude on the vibration characteristics of rubber isolator, Journal of Sound and Vibration 377 ,2016, 216-225.

[4]. C. M. Harris, Allan G. Piersol, Harris,shock and vibration handbook (McGRAW-HILL,2002).

[5]. G. K. Grover, Mechanical vibrations (Nem chand \& bros, 2009) 